tion and economic growth. After conservation measures have been applied, he estimates Italy will be consuming $40 \%$ more energy in the year 2000 than now. "Don't measure that against UK standards. Our per capita consumption is 2.4 tonnes of oil equivalent; you have 3.7 ; so we must make great progress to reach other European countries. We can't possibly stay much behind them if we want to develop our own industry." The $40 \%$ increase corresponds to an annual rate of about $1.4 \%$, and is based on an assumption of economic growth of $2.5 \%$ per year with an "energy elasticity' (ratio between energy and economic growth rates) of some $50 \%$.

Colombo is in the process of constructing his first 5-year plan for CNEN. "In the past everyone has been very superficial: both parliament and government, and CNEN, ENEL and the industry." Now Colombo believes that "we at CNEN must express our opinions forcefully, justify them with numbers and facts, and submit our ideas to a discussion in parliament." Then it is a matter of responding to the political will of parliament and government. Colombo hopes to submit his plan by the end of the summer.

Previously CNEN's energy policy was "very much in the air, something rather abstract". CNEN was moving in many different directions, in each of them "below the necessary threshold" of potential, manpower, and capital. Furthermore CNEN has been hampered by the government's inability to define a politically and publically acceptable nuclear plan. But in any case the previous plan "was too ambitious, and not credible at all".

"There were gigantic plans to build up a huge number of power stations, but the plans were never implemented.

They required almost a menu of different nuclear technologies, which -particularly after the Harrisburg incident--is no longer advisable. We need to concentrate on one type of proven reactor, and to put a great emphasis on the safety and security aspects of that one. I therefore will use my influence and my power-as far as possible-to determine this concentration of effort on one type of reactor. I do not think we have the technical or organisational capability to go ahead in many different directions in nuclear power in Italy."

The reactor will probably be the Westinghouse pressurised water reactor, which has also been chosen in France and Germany; this not because Colombo has any particular attachment to that but because the concentration of international effort and experience on it should make it one of the safest systems.

Nevertheless the Italian industry will continue to work on other reactor systems, like the Tirrhena heavy water reactor presently under construction "to enable the industry to work on the commercialisation of CANDUtype reactors throughout the world". CNEN will also do direct and sponsored research and development of fast breeders and fusion reactors.

On nuclear safety, CNEN is at present both promoter and regulator of nuclear power-an unsatisfactory situation which Colombo expects to be changed sometime next year. At present "they both depend on me" says Colombo. But for the moment he is reluctant to give up the dual role. "We must first make the safety division of CNEN stronger technologically; I want to fortify it a little bit before giving it to somebody else. Secondly, the safety problem in nuclear plants is not just a health problem, it's a matter of checking the design, construction, and operation of very complex technological plants, which requires some technical expertise. If safety is left in the hands of medical people alone, and epidemiologists, they will cover very well the biological part but won't be competent in the other. So we need both, and we need to move towards the creation of an independent organisation. I hope it will be constituted under the premier, who controls both industry and health, allowing the organisation to include both types of competence".

"I am grateful to those who have been against nuclear power, although I do not share their ideas" said Colombo. "They have brought the problem to the surface, and obliged us to be more frank and serious in our considerations." In the past, he said, the nuclear authorities in Italy have been too arrogant in their dealings with the public; it is time to consider clearly and openly all the risks, both with and without nuclear power.

Furthermore, "if we are able to develop alternative sources immediately so that they can penetrate by $7 \%$ by the year 2000 , and take off thereafter, we might even be able to do without fast breeders. But if the rate of penetration is slow, and if nuclear fission is the bridging energy source up to 2020-2030, we will have serious problems with uranium."

Colombo therefore wants to keep fast breeders open as an option, and Italy is already building pilot reprocessing plants "so that when we have to decide, we can decide from a strong position".

Ultimately, however, it is all up to the Italian government. "I'm powerful as far as propositions are concerned" says Colombo "but I'm not the one who decides". Colombo will be submitting his first 5-year plan to the government "in a month or two".

\section{Energy efforts should shift from research to conservation}

ThE US Administration is placing too much emphasis on research into new energy technologies, and not enough into conservation techniques even though the latter have already produced considerable energy savings, according to a paper published by the Union of Concerned Scientists.

Dr Vince Taylor, the author of the paper, points out that improvements in efficiency made by industry since 1973 have contributed twice as much as oil obtained through the Alaska pipeline to the energy needs of the US last year. " $90 \%$ or more of the solution to our energy problems will come from improvement in energy productivity$10 \%$ or less from supply extension. Yet the administrative and budgetary resources are being allocated in just the opposite proportions," Dr Taylor writes.

Dr Taylor lays out what he calls an 'easy path' strategy which, he claims, would redress imbalances in the energy budget by concentrating on factors such as improving the efficiency of motor vehicles and of energy use in domestic and commercial buildings, and selective switching between fuels. This strategy, he says, does not depend for its success on expensive and uncertain long-range $R \& D$ projects.

\section{Carter proposes new fund to clear up chemical wastes}

President Carter has submitted to Congress legislation setting up a $\$ 1.6$ billion fund for cleaning up hazardous chemical waste dumps and the effects of chemical and oil spills, in what one aide has referred to as "the most important environmental legislation" to be proposed by the Administration in the current year.

The President's move has been prompted both by general concerns about the effects of industrial pollution, and more specifically by a number of recent highly-publicised cases in which the previous dumping of toxic wastes has led to serious environmental and health hazards.

Against the advice of a number of federal agencies (although not the Environmental Protection Agency) the President has also decided that the industries responsible for the wastes should carry a large part of the bill for clearing them up. Consequently $80 \%$ of the fund would come through a series of fees imposed on oil refiners and chemical manufacturers. 